\title{
Face Processing Impairments and Delusional Misidentification
} \author{
and KAREL W. DE PAUW ${ }^{4}$ \\ ${ }^{1}$ Department of Psychology, University of Durham, Durham DH1 3LE, UK \\ ${ }^{2}$ School of Psychology, University of Wales College of Cardiff, Cardiff \\ ${ }^{3}$ Department of Psychiatry, Bassetlaw District General Hospital, Worksop \\ ${ }^{4}$ Department of Psychiatry, Doncaster Royal Infirmary, Doncaster
}

ANDREW W. YOUNG ${ }^{1}$ HADYN D. ELLIS $^{2}$, T. KRYSTYNA SZULECKA ${ }^{3}$

\begin{abstract}
We report detailed investigations of the face processing abilities of four patients who had shown symptoms involving delusional misidentification. One (GC) was diagnosed as a Frégoli case, and the other three (SL, GS, and JS) by symptoms of intermetamorphosis. The face processing tasks examined their ability to recognize emotional facial expressions, identify familiar faces, match photographs of unfamiliar faces, and remember photographs of faces of unfamiliar people. The Frégoli patient (GC) was impaired at identifying familiar faces, and severely impaired at matching photographs of unfamiliar people wearing different disguises to undisguised views. Two of the intermetamorphosis patients (SL and GS) also showed impaired face processing abilities, but the third (JS) performed all tests at a normal level. These findings constrain conceptions of the relation between delusional misidentification, face processing impairment, and brain injury.
\end{abstract}

\section{Introduction}

Patients suffering from delusional misidentification syndromes (DMSs) make various characteristic errors in recognizing people. A number of different types of delusional misidentification have been identified. The most well-known are the Capgras delusion (Capgras and Reboul-Lachaux, 1923), in which certain people (usually close relatives) are felt to have been replaced by "dummies" or imposters; the Frégoli delusion (Courbon and Fail, 1927), in which a cunningly disguised persecutor is claimed to be following the patient about; and intermetamorphosis (Courbon and Tusques, 1932), in which a particular person's appearance seems to the patient to transform into that of someone else. Although they are traditionally referred to as "syndromes", it should be noted that there is really only a single defining symptom (i.e. a particular type of delusion) for each of the DMSs.

For several years, interest in explaining delusional misidentification was heavily weighted toward psychodynamic accounts (Berson, 1983). This emphasis, however, has lessened somewhat because of the mounting evidence of organic involvement (usually in the form of clearly demonstrable brain lesions) in all types of delusional misidentification (Joseph, 1986), 
including Capgras' delusion (e.g. Weston and Whitlock, 1971; MacCallum, 1973, 1985; Luaute et al., 1978; Alexander et al., 1979; Wilcox and Waziri, 1983; Lewis, 1987), the Frégoli delusion (de Pauw et al., 1987; Joseph and O'Leary, 1987), and intermetamorphosis (Bick, 1986; Joseph, 1987).

The importance of an organic component in delusional misidentification has been bolstered by the observation that, like some neurological patients, DMS patients can perform poorly on standard neuropsychological tests of face recognition. For example, Shraberg and Weitzel (1979) noted that two Capgras patients made more errors on the Benton test of facial recognition (Benton et al., 1983) than did normal or schizophrenic controls. Morrison and Tarter (1984) also noted impairment on the Benton test in their Capgras patient, and Luaute et al. (1986) and Tzavaras et al. (1986) found that DMS patients showed impairments on the face matching test devised by Tzavaras et al. (1970).

To date, these reports of impairment on neuropsychological tests of face processing in DMS patients have mostly involved Capgras patients, and have relied heavily on the use of tests of unfamiliar face matching. Both the test of Benton et al. (1983) and that devised by Tzavaras et al. (1970) require subjects to match photographs of faces of unfamiliar people, by picking out those which are pictures of the same person. While this is undoubtedly a useful procedure, it only permits limited conclusions to be drawn because there is now strong evidence to suggest that this type of test does not tap abilities involved in the recognition of familiar faces. Benton's (1980) review was among the first to emphasize this point.

In fact, it is now clear that neuropsychological impairment can affect face processing in a number of dissociable ways. Dissociable impairments of familiar face recognition, unfamiliar face matching, and recognition of emotional expressions have been described (for reviews, see Bruce and Young, 1986; Young and Bruce, in press). It is thus necessary to test face processing abilities in ways capable of pinpointing which abilities are impaired and which intact, rather than relying on a single test. This is now done routinely in neuropsychological work (e.g. Bruyer et al., 1983; Sergent and Villemure, 1989; Young and Ellis, 1989).

To make proper use of this approach, it is necessary to have an explicit functional model of the components underlying normal face processing, to guide the investigation of what remains intact or has been impaired by brain injury. A number of closely related theoretical models have been developed for this purpose (e.g., Hay and Young, 1982; Ellis, 1983, 1986; Rhodes, 1985; Bruce and Young, 1986; Bruyer, 1987).

Ellis and Young (1990) have suggested that this approach of detailed testing in terms of an explicit functional model might prove as useful in understanding delusional misidentification as it has proved in neuropsychology. To this end, we report here a systematic investigation of face processing abilities in four DMS patients, using procedures developed in cognitive neuropsychological investigations. Our study is also the first to concentrate on face processing impairments in Frégoli and intermetamorphosis patients. 


\section{Case Descriptions}

Investigations of four DMS patients were carried out. One of these (GC) was a case of Frégoli delusion, whilst the other three (SL, GS, and JS) presented more complex pictures, in each of which intermetamorphosis featured prominently.

\section{Frégoli delusion}

$G C:$ A right-handed divorced woman, born in 1919. At the age of 66 , after a head injury and two transient ischaemic attacks, she developed the delusion that her cousin (who was her only child's father) and a lady friend of his were following her in disguise. She began to accost and harangue strangers and passers-by, demanding that they reveal their true identities.

Following presentation with this symptom in 1985, GC was treated with trifluoperazine which, apart from a relapse when she stopped taking it, was successful in controlling the delusion. EEG recordings carried out around the date of admission and some 8 months later were abnormal, particularly in right temporal regions. CT scan showed a right-sided posterior temporoparietal infarct, and moderate general cortical atrophy. A full report on this case was given by de Pauw et al. (1987), and a further brief description by de Pauw and Szulecka (1988).

GC was seen for the present investigation in two sessions in 1987. She was still taking medication to control the delusion, but she remembered the former incidents well, and was able to describe them in detail. She confided that she still thought "it was them who should have been locked up".

\section{Intermetamorphosis}

$S L$ : A divorced man born in 1957, with a family history of affective disorder (a maternal uncle committed suicide, his mother had numerous admissions for both mania and depression, a brother had treatment for depression) and a personal history of alcohol, amphetamine, cocaine and cannabis abuse. Admitted in 1987, aged 29, with a 6 month history of disruptive and aggressive behaviour during which he mistook his mother for his brother and accused his wife of being the woman who he claimed had pushed him in front of a car at the age of 17 as a result of which he suffered a (real) head injury. $\mathrm{He}$ also thought that his parents were not his own and that he must have been "adopted". During his first admission he believed that he had briefly changed into a female fellow patient and that his psychiatrist was in fact a woman he had met the year before in a London casino.

He made a full recovery after treatment with zuclopenthixol decanoate. His medication was discontinued after 2 years. He subsequently suffered three further psychotic episodes, during the last of which he attacked a local shop owner whom he mistook for a famous snooker player.

The present study reports data from a single testing session with SL, in 1989. 
GS: An unmarried man born in 1956. In 1985, at age 29, he had attacked his mother, claiming that as she put on her glasses she changed into a neighbour he disliked. He also believed that the neighbour sometimes changed into his mother, making him even more angry. On one occasion he had also attacked his father when he changed into a person who had been spying on him. According to GS, these transformations occurred in front of his eyes; there was no element of disguise.

These incidents occurred against a complicated background, including treatment for chronic paranoid schizophrenia for more than 10 years, and various admissions to hospital because of his disturbed and aggressive behaviour. At one time (in 1974) GS had claimed to be the pop singer Donny Osmond, and he had also said on another occasion (also in 1974) that the members of his family were "robots". A brief report was given by de Pauw and Szulecka (1988).

For the present study, GS was seen in two sessions in 1987, and a further follow-up 2 years later, in 1989. His delusions had responded well to treatment with pimozide, but he remained reluctant to talk about them. When the subject was broached he became very tense, admitted that these things had happened, but insisted that they no longer "bothered" him. He was, however, willing to describe at length his exceptional ability to see behind appearances, to what people are "really" like.

FS: A single man born in 1957. Admitted in 1988, aged 30, with a 4 month history of bizarre beliefs and behaviour. He had become infatuated with a woman who had once lived near his house, and was convinced that she was in love with him because she seemed to appear wherever he went. This belief was maintained despite the fact that she had never approached him and later rejected all his amorous overtures. JS began to misidentify other women he met for this woman, including his mother, who sometimes appeared to change into her; he also thought that strangers resembled people connected with her, such as her parents.

At the age of $18 \mathrm{JS}$ had begun to experience fainting spells, preceded by shoulder pains and a foul smell. An EEG demonstrated abnormal activity, with a right mid-posterior temporal emphasis, but he received no treatment. Six years later he sustained head injuries on two occasions. Temporal lobe epilepsy was diagnosed at the age of 26 , for which JS was treated with carbamazepine. He stopped his medication about 18 months prior to his psychiatric hospitalization. He was treated with haloperidol and carbamazepine, and his delusional beliefs resolved. Two subsequent EEGs demonstrated no evidence of epilepsy or any other localized cerebral pathology. A full report on this case is given by de Pauw and Szulecka (in prep.).

For the present investigation, JS was tested in a single session in 1989.

\section{Face Processing Tasks}

Each of the DMS patients was tested on tasks intended to examine different aspects of face processing involving recognition of emotional facial expres- 
sions, identification of familiar faces, matching of unfamiliar faces, and memory for faces of unfamiliar people. These are described in turn, followed by the other perceptual tests used. The DMS patients' performances on the face processing tasks are then considered separately for the Frégoli case (GC) and the three intermetamorphosis cases (SL, GS, and JS).

\section{Recognition of emotional facial expressions}

A task involving labelling emotional facial expressions was given. This used 24 facial expression photographs from the Ekman and Friesen (1976) series, with four of these corresponding to each of the emotions Happiness, Sadness, Surprise, Fear, Anger, and Disgust. The face photographs were presented one at a time, with a list of the six possible emotion labels printed below each face, in random order. The task involved choosing the correct emotion label for each face. Six practice trials were given at the start of the task, using photographs which did not appear in the main series of trials.

Control data for GC were taken from a series of normal men of comparable age (34 men, aged 65-75 years were used as controls for the expression labelling task) who form the control group for a neuropsychological study using this task carried out at the Radcliffe Infirmary, Oxford (see de Haan, Young and Newcombe, in press). Control subjects for SL, GS, and JS were 10 men of comparable age (25-35 years).

\section{Identification of familiar faces}

To test ability to identify familiar faces, patients were given a version of a "faces line-up" which has been used in neuropsychological studies (e.g. A. Ellis et al., 1989; Flude et al., 1989; Hanley, et al., 1989; de Haan et al., in press; Hanley et al., in press).

The faces line-up consists of 60 face photographs; 20 of highly familiar people (Margaret Thatcher, the Queen Mother, Jimmy Savile, etc.), 20 less familiar people (Max Bygraves, David Attenborough, Dora Bryan, etc.), and 20 unfamiliar people (minor celebrities and local politicians from two towns in north-west England). There are also 14 practice faces.

Patients were shown each face photograph one at a time, and asked whether or not it was a familiar person and, if so, his or her occupation and name. From their responses, scores were derived for the number of high familiarity faces given a correct occupation, and the number correctly named. A score for the number of unfamiliar faces correctly rejected as unfamiliar was also calculated, to give some idea of the rate at which details were confabulated.

Control data for GC were taken from 28 men of comparable age from the series of normal men tested at the Radcliffe Infirmary, Oxford (de Haan et al., in press). Control subjects for SL, GS, and JS were 10 men of comparable age (25-35 years). Data for the 20 "less familiar" faces are not 
reported, because control subjects showed high variance in their responses to these, indicating that a number were unknown to controls.

\section{Unfamiliar face matching}

Two separate tests of unfamiliar face matching were used. First, the Benton Test of Facial Recognition (Benton et al., 1983), which has been used in several previous investigations. In this test, subjects have to choose which of six simultaneously presented photographs of unfamiliar faces are pictures of the same person as a simultaneously presented target face photograph. The test includes items involving choice of identical photographs, or transformations of orientation and lighting, but these are pooled into an overall composite score. The patients' performances were evaluated by reference to the test's norms (Benton et al., 1983).

The second unfamiliar face matching test examined ability to match disguised faces. Tzavaras et al. (1970) had included items of this type in their unfamiliar face matching battery, and it seemed a particularly interesting test for our Frégoli patient, GC. A "disguise" task was therefore originally produced for GC, but was then given to the other patients as well.

The "disguise" task involved faces of eight unfamiliar people, which were photographed in undisguised form, and then wearing a variety of disguises (spectacles, false beards, moustaches, and wigs). Two separate test sheets were made, on each of which there was one version of each face in the top row, and then a $3 \times 4$ matrix below, in which each of the four people from the top row appeared in three further disguised or undisguised forms. Subjects were asked to pick out the photographs from the $3 \times 4$ matrix which showed each of the four top row people. Both test sheets were given, leading to an overall score out of a maximum of 24 possible correct choices on this "disguise" test. An example of one of the sheets is shown in Fig. 1.

Control data for GC were assembled by testing 10 women of comparable age (range, 63-75 years), and for the intermetamorphosis patients (SL, GS, and JS) 10 male controls aged 25-35 years were run.

\section{Memory for faces of unfamiliar people}

Memory for faces of unfamiliar people was tested with the Recognition Memory Test (RMT) produced by Warrington (1984). This involves the presentation of 50 photographs of faces of unfamiliar people for $3 \mathrm{sec}$ each, whilst the subject performs an orienting task of deciding whether each face is "pleasant" or "unpleasant". Recognition memory for the faces is then measured immediately, by working through a booklet of 50 pairs of face photographs. One member of each pair is a face from the original series; the subject's task is to choose this face.

A parallel version of the RMT using printed words as stimuli is also available, and was given to the patients in this study.

The patients' performance of the face and word components of the RMT was evaluated by reference to the test's norms. 


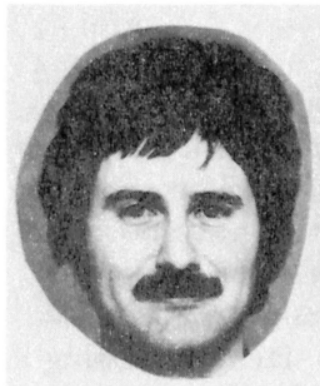

A
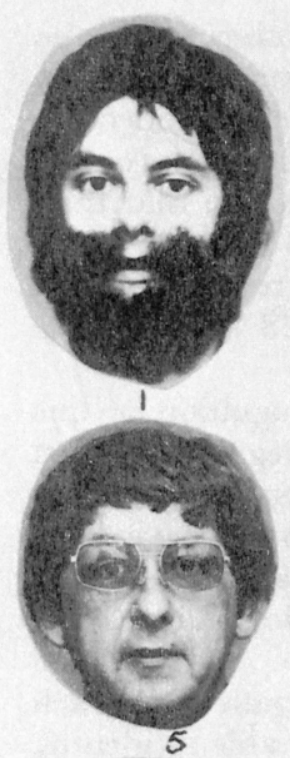

5

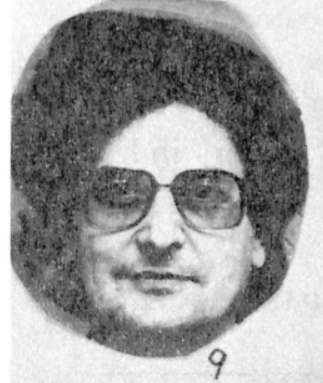

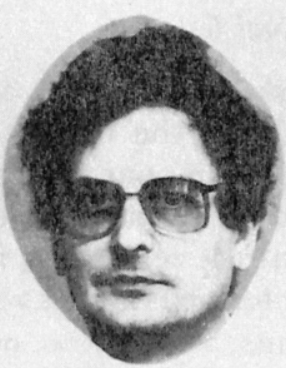

B
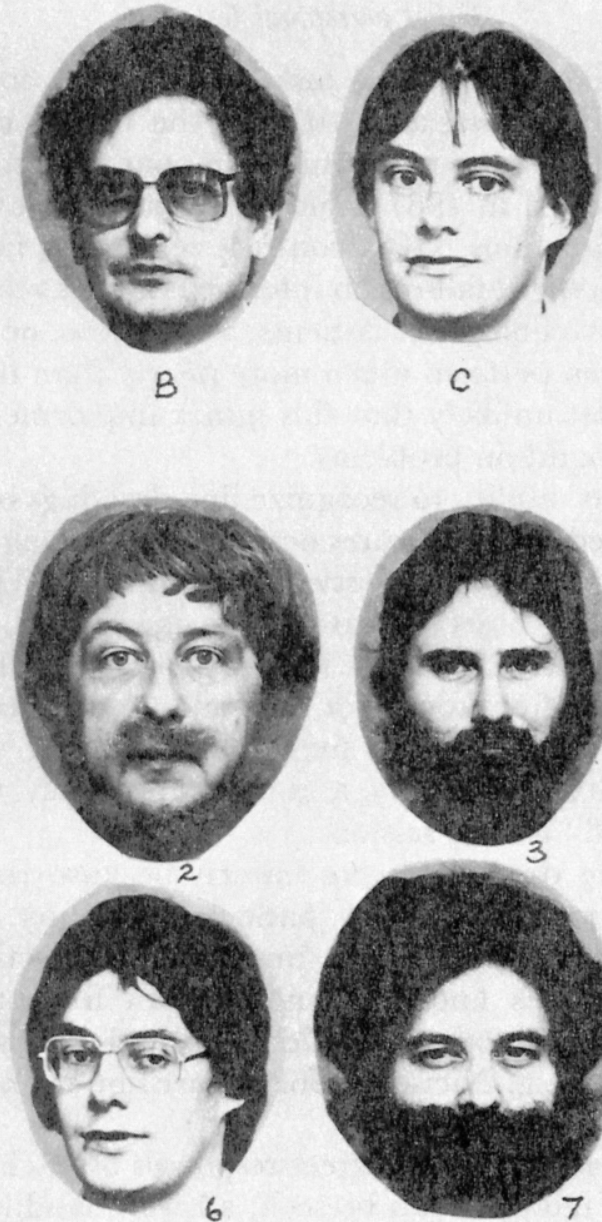

6
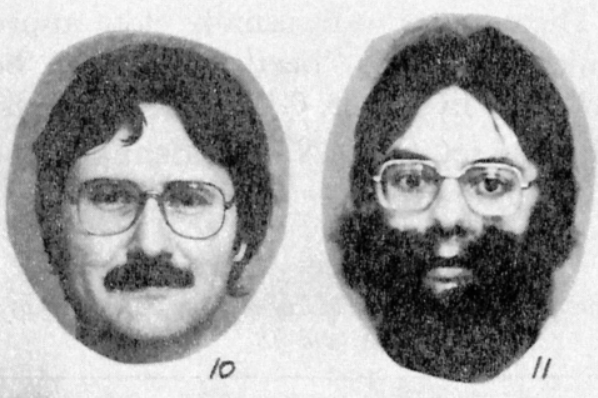

c

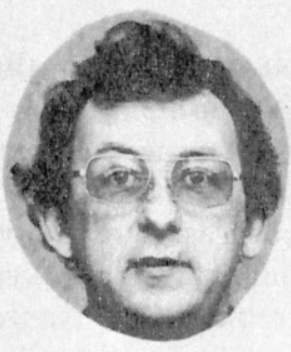

D
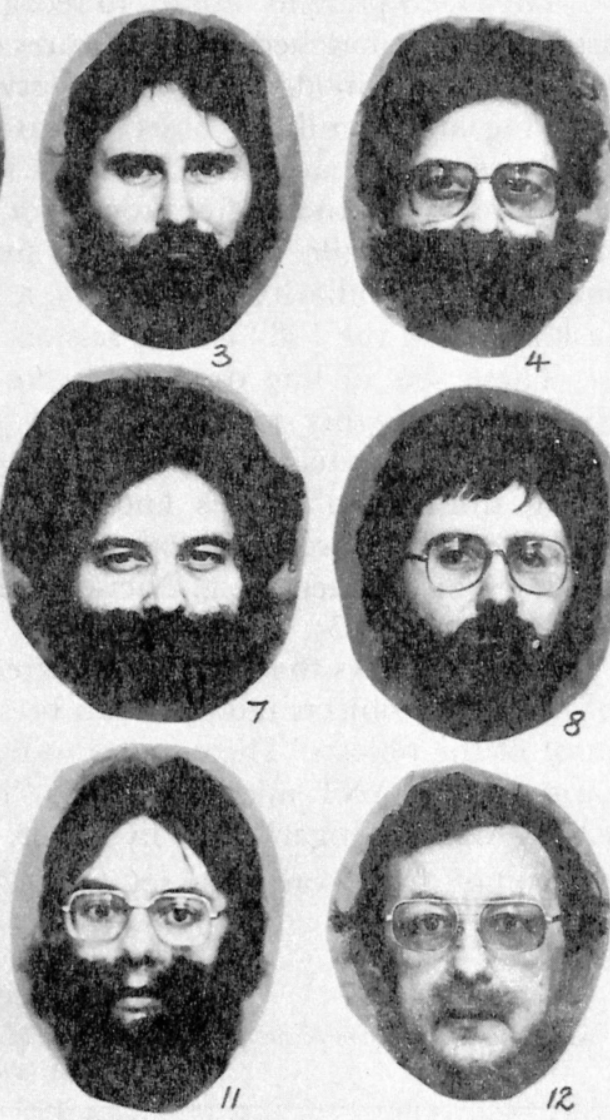

Fig. 1. Example of test sheet from "disguise" task. 


\section{Other perceptual tests}

In addition to the face processing tasks, the spatial contrast sensitivity function of all four patients was assessed using the Vistech charts, in order to determine whether there was a perceptual component to any face processing problems. SL, GS (tested in 1987), and JS all turned out to have normal contrast sensitivity functions. GC's contrast sensitivity function was near normal, but showed a slight fall-off on intermediate (6 cycles/degree) spatial frequencies. Neuropsychological patients who show no face processing impairment at all often perform much more poorly than this (Newcombe $e t$ al., 1989), so it is most unlikely that this minor impairment has any direct bearing on GC's recognition problems.

The DMS patients' ability to recognize line drawings of objects was also assessed using matched sets of pictures described by Young and Ellis (1989), taken from the Snodgrass and Vanderwart (1980) series. These included sets of living and non-living objects, matched on familiarity, complexity, and name frequency; and sets of objects that are often handled (so that their structure is well-known from touch) or only seldom handled (so that there is little or no tactile experience of the object's overall structure), again matched on familiarity, complexity, and name frequency. GS was given the task in one of the 1987 testing sessions.

These sets of line drawings were chosen because recognition of line drawings is highly problematic for patients with any degree of object agnosia, and because category-specific impairments affecting living or nonliving things and objects known or not known from touch have been described in neuropsychological studies of visual agnosia and semantic memory impairment (e.g. Nielsen, 1962; Warrington and Shallice, 1984; Warrington, 1985).

Table 1 shows the number of correct responses by each patient, for each of the sets of objects used. As can be seen, all were readily able to identify most of the objects. Their errors were usually close approximations to the targets (GC: ANT misidentified as "beetle", FLY as "bee or wasp", and LEOPARD as "tiger" from living set, GUITAR as "violin", and VIOLIN as "guitar" from non-living set; GS: ANT misidentified as "spider" in living

TABLE 1. Recognition accuracy for matched sets of line drawings of objects by DMS patients GC, SL, $G S$, and $7 S$

\begin{tabular}{|c|c|c|c|c|}
\hline & \multicolumn{2}{|c|}{$\begin{array}{l}\text { Frégoli } \\
\text { patient }\end{array}$} & \multicolumn{2}{|c|}{$\begin{array}{l}\text { Intermetamorphosis } \\
\text { patients }\end{array}$} \\
\hline & $G C$ & $S L$ & $G S$ & $\mathcal{F S}$ \\
\hline Living: & $17 / 20$ & $20 / 20$ & $19 / 20$ & $20 / 20$ \\
\hline Non-living: & $18 / 20$ & $20 / 20$ & $19 / 20$ & $20 / 20$ \\
\hline Often handled: & $20 / 20$ & & $20 / 20$ & \\
\hline Seldom handled: & $20 / 20$ & & $20 / 20$ & \\
\hline
\end{tabular}


set, no response to SLEDGE in non-living set). It can be concluded that the DMS patients' ability to recognize objects was largely unimpaired. There was no pronounced object agnosia, and no evidence of any semantic memory impairment beyond GC's isolated confusion of leopard and tiger.

These additional tests of visual perceptual and recognition abilities thus showed nothing wrong with the patients that could in any way be considered to have contributed to their DMSs.

\section{Face Processing and the Frégoli Delusion}

GC's performance of the face processing tasks is summarized in Table 2. The scores reported come from our two testing sessions with her in 1987, with the exception of the Warrington RMT, which had already been given.

As Table 2 shows, GC was able to label facial expressions without difficulty, and she was unimpaired on the Benton unfamiliar face matching test. On the Warrington RMT her score for faces (36/50 correct) was at the low end of the normal range (7th percentile; de Pauw et al., 1987). Her recognition memory for words was good (47/50 correct), and there was a significant discrepancy between her relatively poor and good recognition memory for faces and words respectively.

TABLE 2. Performance of Frégoli patient GC on face processing tasks, and means and standard deviations for control subjects of comparable age

\begin{tabular}{|c|c|c|c|}
\hline & \multirow{2}{*}{$\begin{array}{c}\text { Frégoli } \\
\text { patient } \\
\text { GC }\end{array}$} & \multicolumn{2}{|c|}{ Controls } \\
\hline & & Mean & $S D$ \\
\hline \multicolumn{4}{|l|}{ FACIAL EXPRESSIONS } \\
\hline Labelling: & $20 / 24$ & 21.1 & 1.7 \\
\hline \multicolumn{4}{|l|}{ FACES LINE-UP } \\
\hline \multicolumn{4}{|l|}{ High familiarity faces } \\
\hline Occupation: & $15 / 20 *$ & 18.86 & 1.15 \\
\hline Name: & $8 / 20 *$ & 16.25 & 2.81 \\
\hline \multicolumn{4}{|l|}{ Unfamiliar faces } \\
\hline Correct rejections: & $20 / 20$ & & \\
\hline \multicolumn{4}{|c|}{ UNFAMILIAR FACE MATCHING } \\
\hline Benton test: & $42 / 54$ & & \\
\hline "Disguise" task: & $13 / 24 * *$ & 22.30 & 2.16 \\
\hline \multicolumn{4}{|l|}{ RECOGNITION MEMORY } \\
\hline Warrington RMT: Faces: & $36 / 50 \dagger$ & 42.26 & 3.44 \\
\hline Warrington RMT: Words: & $47 / 50 \dagger$ & 42.63 & 5.21 \\
\hline
\end{tabular}

$*=$ more than $2.5 \mathrm{SDs}$ below control mean.

$* *=$ more than 4.0 SDs below control mean.

$\dagger=$ significant discrepancy between faces and words RMT scores $(<5$ th percentile) 
GC showed impaired ability to identify familiar faces, with poor scores both on giving occupations and for naming the high familiarity faces. She did, however, correctly reject all the unfamiliar faces, showing that she did not confabulate. In particular, she did not suggest that any of the faces might be her cousin or his friend, in disguise or otherwise.

GC's most marked impairment, however, was on the "disguise" task. She found this quite exceptionally difficult, and was very slow and hesitant in her choices. Her performance was above chance level (chance $=6 / 24$ correct), but was very poor in relation to controls (4.31 SDs below the control mean).

\section{Face Processing and Intermetamorphosis}

Table 3 summarizes the results from the main face processing tasks for the three intermetamorphosis patients SL, GS, and JS, and includes separate tabulation of GS's assessments in 1987 (column GS1) and 1989 (column GS2). We will consider each patient in turn.

TABLE 3. Performance of intermetamorphosis patients $S L, G S$, and $7 S$ on face processing tasks, and means and standard deviations for control subjects of comparable age. Data from two separate assessments of $G S$ are presented, with a two-year interval between them

\begin{tabular}{|c|c|c|c|c|c|c|}
\hline & \multicolumn{4}{|c|}{$\begin{array}{c}\text { Intermetamorphosis } \\
\text { patients }\end{array}$} & \multicolumn{2}{|c|}{ Controls } \\
\hline & $S L$ & GS1 & GS2 & $\mathcal{J S}$ & Mean & $S D$ \\
\hline \multicolumn{7}{|l|}{ FACIAL EXPRESSIONS } \\
\hline Labelling: & $21 / 24$ & $12 / 24 * *$ & $17 / 24 * *$ & $21 / 24$ & 22.00 & 1.24 \\
\hline \multicolumn{7}{|l|}{ FACES LINE-UP } \\
\hline \multicolumn{7}{|l|}{ High familiarity faces } \\
\hline Occupation: & $9 / 20 * *$ & $15 / 20$ & $17 / 20$ & $17 / 20$ & 17.58 & 1.08 \\
\hline Name: & $8 / 20 * *$ & $11 / 20^{*}$ & $12 / 20^{*}$ & $15 / 20$ & 16.17 & 1.53 \\
\hline \multicolumn{7}{|l|}{ Unfamiliar faces } \\
\hline Correct rejections: & $20 / 20$ & $20 / 20$ & $20 / 20$ & $20 / 20$ & & \\
\hline \multicolumn{7}{|l|}{ UNFAMILIAR FACE } \\
\hline \multicolumn{7}{|l|}{ MATCHING } \\
\hline Benton test: & $41 / 54$ & $43 / 54$ & $39 / 54$ & $50 / 54$ & & \\
\hline "Disguise" task: & $20 / 24$ & $17 / 24$ & & $21 / 24$ & 21.60 & 1.90 \\
\hline \multicolumn{7}{|l|}{ RECOGNITION MEMORY } \\
\hline Warrington RMT: Faces: & $29 / 50 \dagger * *$ & & $38 / 50 \dagger$ & $39 / 50$ & 43.75 & 3.57 \\
\hline Warrington RMT: Words: & $50 / 50 \dagger$ & & $49 / 50 \dagger$ & $44 / 50$ & 45.75 & 3.62 \\
\hline
\end{tabular}

$*=$ more than $2.5 \mathrm{SDs}$ below control mean.

**= more than $4.0 \mathrm{SDs}$ below control mean.

$\dagger=$ significant discrepancy between faces and words RMT scores $(<5$ th percentile).

GS1 = GS's performance in 1987

GS2 = GS's performance in 1989 
$S L$ : SL could label facial expressions without difficulty, and also had no problems with the unfamiliar face matching tasks. However, he was very impaired at identifying the highly familiar faces, both in terms of giving occupations and names. This impairment was not as extreme as that usually found in cases of prosopagnosia, where virtually no faces at all can be recognized overtly (e.g. de Haan et al., 1987), but it was nonetheless very severe. SL's memory for faces of unfamiliar people was also very defective (score 29/50 on the Warrington RMT for faces, where chance $=25 / 50$ ), yet he showed perfect retention of words $(50 / 50)$ across the same memory interval.

GS: The pattern of GS's performance was consistent across the initial (1987) and later (1989) assessments, with poor labelling of facial expressions, and poor naming of familiar faces. The problem with familiar faces seemed primarily to involve name retrieval rather than recognition, because GS was at the low end of the normal range for giving occupations in 1987 (using our criterion for impairment of performance 2.5 SDs from the control mean), and unimpaired for occupations in 1989.

On unfamiliar face matching and the Warrington RMT for faces GS performed at a level toward the low end of the normal range, but he showed good recognition memory for words (49/50 correct). Although he was not impaired on the faces part of the RMT as such, the discrepancy between his relatively poor performance with faces and good recognition memory for words was beyond the 5th percentile in Warrington's (1984) norms.

The poor labelling of facial expressions was especially marked in the initial (1987) assessment, but GS remained very impaired at this on followup in 1989 (performance still more than $4.0 \mathrm{SDs}$ below control mean). It was not due to a problem in retrieval of appropriate expression labels, because these were given with each item as part of the test. Moreover, we found that GS did just as badly (or worse) when he was asked simply to decide whether or not two faces showed same or different expressions. His behaviour during this task and during the expression labelling test was extraordinary. It was impossible to get him to carry out the task as intended, because of his persistent assertion that he could see the "real" expressions, and lengthy confabulations concerning the circumstances and character of each person. When pressed to set aside these remarkable abilities of his own, and simply decide what the people might be thought to be feeling by those not so gifted, he became dismissive. The expression matching task (which, fortunately, was not part of our standard battery) had to be abandoned, but we managed to persuade him to choose what he considered to be the least inappropriate label for each item in the expression labelling task.

These bizarre responses to facial expressions were not typical of GS's approach to other face processing tasks. He performed the unfamiliar face matching tasks (and especially the Benton test) quickly and confidently (though he only scored at the bottom of the normal range on the disguise task), and he did not confabulate responses to any of the unfamiliar faces in the faces line-up (20/20 of these were correctly rejected as unfamiliar). Thus his responses to the emotional expression tests did seem to reflect a genuine 
(if unusual). impairment centred on inability to understand other people's feelings, rather than any more general intellectual incapacity.

Examination of GS's errors in the expression labelling task showed a noticeable tendency to misinterpret expressions of fear or disgust as "anger". These accounted for $5 / 12$ of his errors in 1987, and 3/7 errors in 1989. When he was given a simplified version of the task (in 1987), with only disgust, fear, and anger used as expressions, and only these labels offered as choices on each trial, GS made 5/12 incorrect choices, in all of which his conclusion was that the face showed anger.

7S: JS was unimpaired for all of the tasks.

\section{Discussion}

Our findings demonstrate a number of face processing impairments in DMS patients, and thus lend weight to other reports of face processing problems occurring in association with delusional misidentification. The implications of these findings, however, need to be carefully considered.

The findings with GC are perhaps the most intriguing, since her poor performance of the "disguise" test seems to parallel her delusion that she was followed by her cunningly disguised relative and his accomplice. GC's inability to cope with the "disguise" test was doubly notable in the context of her intact performance on the Benton unfamiliar face matching test, implying that there was nothing directly wrong with her ability to see or match photographs of faces.

We have suggested elsewhere (Ellis and Young, 1990) that the Frégoli delusion must involve impaired decision mechanisms, which allow the patient to accept an inappropriate evaluation of perceptual evidence. The visual system correctly signals that the identity of a seen person is not that of the persecutor, but the "disguise" hypothesis is then given undue weight. It will thus be interesting to know whether other Frégoli patients share GC's inability properly to disentangle the effects of disguise.

For the intermetamorphosis patients, the pattern is less clear. One patient (JS) was unimpaired on all of our tests. The other two patients tended to show somewhat contrasting patterns, with GS being very impaired on expression labelling whereas SL had no problem with this task, and SL being very impaired at identification of familiar faces (in terms of his ability to give correct occupations) whereas GS experienced fewer problems in this direction. It is true that GS did have a problem with name retrieval to familiar faces, but again this contrasts with SL. Although SL did not get many names correct, this was because he failed to recognize many of the familiar faces at all (i.e. he was unable to give semantic information or a name to these faces). For those faces that he could recognize $(9 / 20$ of the highly familiar faces), name retrieval was clearly not difficult for SL (eight of these nine were named correctly).

On the Warrington recognition memory test for faces, SL's performance was clearly very impaired (29/50 correct), in contrast to his excellent 
memory for words (50/50). GS's performance was nothing like as poor for faces $(38 / 50$ correct), but it was again significantly worse than his very good recognition memory for words (49/50 correct). Thus both SL and GS tended to show a similar pattern of poorer performance with faces than words on this task, and we note that the Frégoli patient, GC, had also shown this pattern.

Hence, for the intermetamorphosis cases, we have a relatively complex picture of contrasting patterns of impairment on identification of faces by occupation and labelling of emotional expressions for SL and GS, together with at least some impairment of recognition memory for unfamiliar faces in each case, and an additional problem of name retrieval with GS.

It is possible that there may be different variants of intermetamorphosis. This has been noted by Silva et al. (1989), who also drew attention to the fact that the Capgras and intermetamorphosis delusions may co-exist in some patients. There did seem to be an element of this for GS, who had claimed at one point that his family were "robots". SL had also denied that his parents were his own, and maintained that he had been adopted. JS had not shown overt signs of the Capgras delusion, but a noteworthy feature of his case was the combination of intermetamorphosis and erotomania (de Pauw and Szulecka, in prep.).

It is perhaps worth noting that none of our patients was experiencing their delusions at the time of testing; all had been effectively controlled by medication. This point, however, also applies to most of the other studies that have reported face processing impairments in DMS patients. Nonetheless, it remains possible that testing during the "florid" state might reveal a different picture.

We think that two points deserve particular emphasis. The first is that DMS patients can have face processing impairments even when they are no longer deluded, and that these can be quite longstanding (as in GS's case). This is consistent with some form of organic involvement in the production of DMS. The second point is that not all DMS patients fit this characterization. In our study, no problems whatsoever were found for JS. Hence, longstanding face processing impairment is not a necessary feature of DMS. In such cases it may be that whatever organic causes were involved have resolved, it may be that they were never present at all, or it may be that they did not interfere with the face processing abilities measured by conventional neuropsychological procedures.

Whichever of these possibilities turns out to be correct, they force us to think more carefully about the relation between face processing impairments, organic brain injury, and DMS. Nothing in the studies reported to date (including our own) implies that face processing impairments of the type we have investigated are actually sufficient to cause DMS. They do seem to be correlated with DMS, but this observation leaves open a variety of possibilities, ranging from anatomical coincidence (in which the face processing impairments would be held to occur because they involve neurological structures adjacent to or even overlapping those implicated in the production of DMS) to a more directly causal role. 
A little reflection shows that the "direct causation" hypothesis cannot be correct. The tests we have used are standard in neuropsychological research (as we pointed out, even the "disguise" test, which was the closest to being tailor-made for this investigation, parallels one used by Tzavaras et al., 1970). Many neuropsychological patients perform as poorly, or more poorly on them than did the DMS cases reported here. But the large majority of these neuropsychological patients with face processing impairments do not experience DMS.

In making this point, we do not seek to question the now considerable evidence of organic involvement in DMS, but we do want to open up the issue as to how this should figure in a satisfactory account. As we have previously noted (Ellis and Young, 1990), if there is a causal connection between brain injury, face processing impairment and DMS, it operates in a relatively subtle way. One possibility is that the face processing problems do not themselves cause the delusions, but that they may play a role in allowing them to achieve such a grip on the patients' lives, by making it much harder to arrive at contradictory evidence. This would obviously be especially the case when impaired decision mechanisms are involved, as seemed to happen for GC. Alternatively, it may be the case that DMSs are only found when a particular combination of organic impairments is involved (e.g. Lewis, 1987), as has been suggested for the related problem of reduplicative paramnesia (Kapur et al., 1988).

At the moment, we can only begin to pose what we hope are the appropriate questions. To find out whether they can be satisfactorily answered will require further detailed case studies of individual DMS patients.

\section{Acknowledgements}

We are grateful to Deborah Hellawell (University of Nottingham) for assistance in preparing the "disguise" task, and to Dr Freda Newcombe (MRC Neuropsychology Unit, Radcliffe Infirmary, Oxford) for permission to report control data taken from her own investigations.

\section{References}

Alexander, M. P., Stuss, D. T. and Benson, D. F. (1979). Capgras syndrome: a reduplicative phenomenon. Neurology, 29, 334-339.

Benton, A. L. (1980). The neuropsychology of facial recognition. American Psychologist, 35, $176-186$.

Benton, A. L., Hamsher, K. de S., Varney, N. and Spreen, O. (1983). "Contributions to Neuropsychological Assessment: a Clinical Manual". Oxford University Press, Oxford.

Berson, R. J. (1983). Capgras' syndrome. American Fournal of Psychiatry, 140, 969-978.

Bick, P. A. (1986). The syndrome of intermetamorphosis. Bibliotheca Psychiatrica, 164, 131135.

Bruce, V. and Young, A. (1986). Understanding face recognition. British Fournal of Psychology, 77, 305-327.

Bruyer, R. (1987). "Les Mecanismes de Reconnaissance des Visages”. Presses Universitaires de Grenoble, Grenoble. 
Bruyer, R., Laterre, C., Seron, X., Feyereisen, P., Strypstein, E., Pierrard, E. and Rectem, D. (1983). A case of prosopagnosia with some preserved covert remembrance of familiar faces. Brain and Cognition, 2, 257-284.

Capgras, J. and Reboul-Lachaux, J. (1923). L'illusion des "sosies" dans un délire systématisé chronique. Bulletin de la Société Clinique de Médicine Mentale, 1, 6-16.

Courbon, P. and Fail, G. (1927). Syndrome d'"illusion de Frégoli" et schizophrénie. Bulletin de la Société Clinique de Médicine Mentale, 15, 121-125.

Courbon, P. and Tusques, J. (1932). Illusions d'intermetamorphose et de charme. Annales Medico-Psychologiques, 14, 401-406.

De Haan, E. H. F., Young, A. W. and Newcombe, F. (1987). Face recognition without awareness. Cognitive Neuropsychology, 4, 385-415.

De Haan, E. H. F., Young, A. W. and Newcombe, F. (in press). A dissociation between the sense of familiarity and access to semantic information concerning familiar people. European Journal of Cognitive Psychology.

De Pauw, K. W. and Szulecka, T. K. (1988). Dangerous delusions: violence and the misidentification syndromes. British Fournal of Psychiatry, 152, 91--96.

De Pauw, K. W. and Szulecka, T. K. (in prep.). The omnipresent lover: a case of erotomania and intermetamorphosis.

De Pauw, K. W., Szulecka, T. K. and Poltock, T. L. (1987). Frégoli syndrome after cerebral infarction. Fournal of Nervous and Mental Disease, 175, 433-438.

Ekman, P. and Friesen, W. (1976). "Pictures of Facial Affect". Consulting Psychologists Press, Palo Alto, Ca.

Ellis, A. W., Young, A. W. and Critchley, E. M. R. (1989). Loss of memory for people following temporal lobe damage. Brain, 112, 1469-1483.

Ellis, H. D. (1983). The role of the right hemisphere in face perception. In "Functions of the Right Cerebral Hemisphere" (Ed A. W. Young). Academic Press, London. 33-64.

Ellis, H. D. (1986). Processes underlying face recognition. In R. Bruyer (Ed.). "The Neuropsychology of Face Perception and Facial Expression". Erlbaum, New Jersey, pp. $1-27$.

Ellis, H. D. and Young, A. W. (1990). Accounting for delusional misidentifications. British Journal of Psychiatry, 156.

Flude, B. M., Ellis, A. W. and Kay, J. (1989). Face processing and name retrieval in an anomic aphasic: names are stored separately from semantic information about familiar people. Brain and Cognition, 11, 60-72.

Hanley, J. R., Young, A. W. and Pearson, N. (1989). Defective recognition of familiar people. Cognitive Neuropsychology, 6, 179-210.

Hanley, J. R., Pearson, N. A. and Young, A. W. (in press). Impaired memory for new visual forms. Brain.

Hay, D. C. and Young, A. W. (1982). The human face. In A. W. Ellis (Ed.). "Normality and Pathology in Cognitive Functions". Academic Press, London. 173-202.

Joseph, A. B. (1986). Focal central nervous system abnormalities in patients with misidentification syndromes. Bibliotheca Psychiatrica, 164, 68-79.

Joseph, A. B. (1987). Delusional misidentification of the Capgras and intermetamorphosis types responding to clorazepate. Acta Psychiatrica Scandinavica, 75, 330-332.

Joseph, A. B. and O'Leary, D. H. (1987). Anterior cortical atrophy in Fregoli syndrome. Journal of Clinical Psychiatry, 48, 409-411.

Kapur, N., Turner, A. and King, C. (1988). Reduplicative paramnesia: possible anatomical and neuropsychological mechanisms. Journal of Neurology, Neurosurgery, and Psychiatry, 51, 579-581.

Lewis, S. W. (1987). Brain imaging in a case of Capgras' syndrome. British Journal of Psychiatry, 150, 117-121.

Luaute, J. P., Bidault, E. and Thionville, M. (1978). Syndrome de Capgras et organicité cérébrale: a propos d'une malade étudiée par un test de reconnaissance des visages et par la scanographie. Annales Medico-Psychologiques, 5, 803-815.

MacCallum, W. A. G. (1973). Capgras symptoms with an organic basis. British Journal of Psychiatry, 123, 639-642.

MacCallum, W. A. G. (1985). An expanded Capgras syndrome. In "Psychiatry: the State of 
the Art, 1". (Eds P. Pichot, P. Berne, R. Wolf and K. Thau), Plenum, New York, 831840.

Morrison, R. L. and Tarter, R. E. (1984). Neuropsychological findings relating to Capgras syndrome. Biological Psychiatry, 19, 1119-1128.

Newcombe, F., de Haan, E. H. F., Ross, J. and Young, A. W. (1989). Face processing, laterality, and contrast sensitivity. Neuropsychologia, 27, 523-538.

Nielsen, J. (1962). "Agnosia, Apraxia, Aphasia: their Value in Cerebral Localization". Hafner, New York. (Originally published in 1936).

Rhodes, G. (1985). Lateralized processes in face recognition. British Journal of Psychology, 76, 249-271.

Sergent, J. and Villemure, J-G. (1989). Prosopagnosia in a right hemispherectomized patient. Brain, 112, 975-995.

Shraberg, D. and Weitzel, W. D. (1979). Prosopagnosia and the Capgras syndrome. Fournal of Clinical Psychiatry, 40, 313-316.

Silva, J. A., Leong, G. B., Shaner, A. L. and Chang, C. Y. (1989). Syndrome of intermetamorphosis: a new perspective. Comprehensive Psychiatry, 30, 209-213.

Snodgrass, J. G. and Vanderwart, M. (1980). A standardized set of 260 pictures: norms for name agreement, image agreement, familiarity and visual complexity. Fournal of Experimental Psychology: Human Learning and Memory, 6, 174-215.

Tzavaras, A., Hécaen, H. and Le Bras, H. (1970). Le problème de la specificité du déficit de la reconnaissance du visage humain lors des lésions hémisphériques unilatérales. Neuropsychologia, 8, 403-416.

Tzavaras, A., Luaute, J. P. and Bidault, E. (1986). Face recognition dysfunction and delusional misidentification syndromes (DMS). In "Aspects of Face Processing" (Eds H. D. Ellis, M. A. Jeeves, F. Newcombe and A. Young). Martinus Nijhoff, Dordrecht. pp. 310-316.

Warrington, E. K. (1984). "Recognition Memory Test". NFER-Nelson, Windsor.

Warrington, E. K. (1985). Agnosia: the impairment of object recognition. In "Handbook of Clinical Neurology, vol 1: Neuropsychology" (Ed. J. A. M. Frederiks). Elsevier, Amsterdam, pp. 333--349.

Warrington, E. K. and Shallice, T. (1984). Category specific semantic impairments. Brain, 107, 829-854.

Weston, M. J. and Whitlock, F. A. (1971). The Capgras syndrome following head injury. British Fournal of Psychiatry, 119, 25-31.

Wilcox, J. and Waziri, R. (1983). The Capgras symptom and nondominant cerebral dysfunction. Fournal of Clinical Psychiatry, 44, 70-72.

Young, A. W. and Bruce, V. (in press). Perceptual categories and the computation of "grandmother". European Fournal of Cognitive Psychology.

Young, A. W. and Ellis, H. D. (1989). Childhood prosopagnosia. Brain and Cognition, 9, 16-47. 


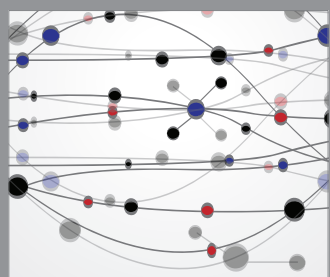

The Scientific World Journal
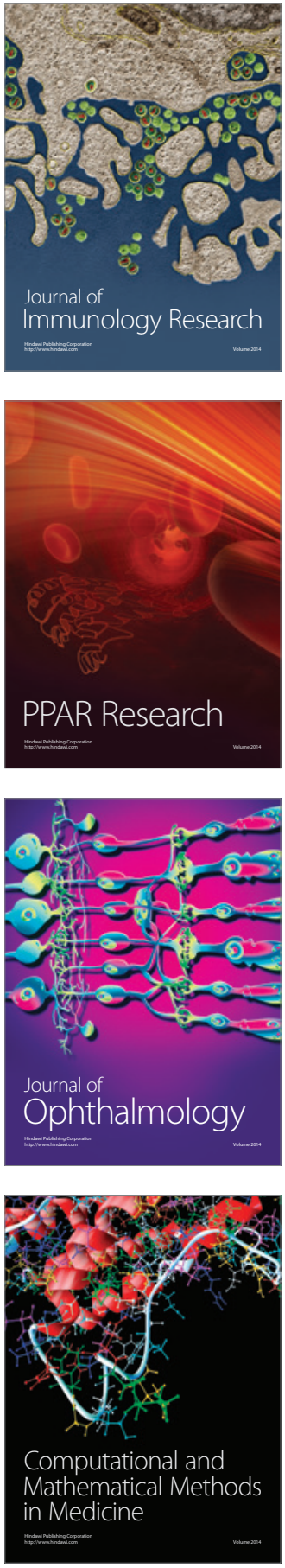

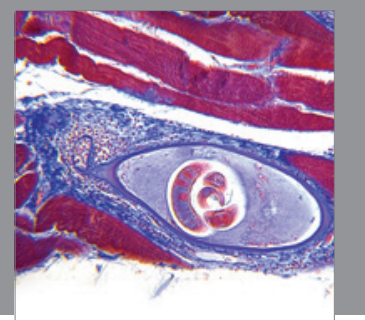

Gastroenterology

Research and Practice
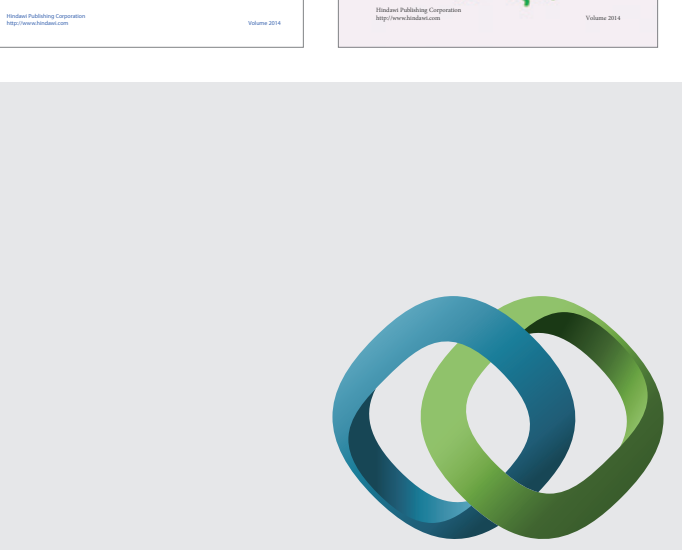

\section{Hindawi}

Submit your manuscripts at

http://www.hindawi.com
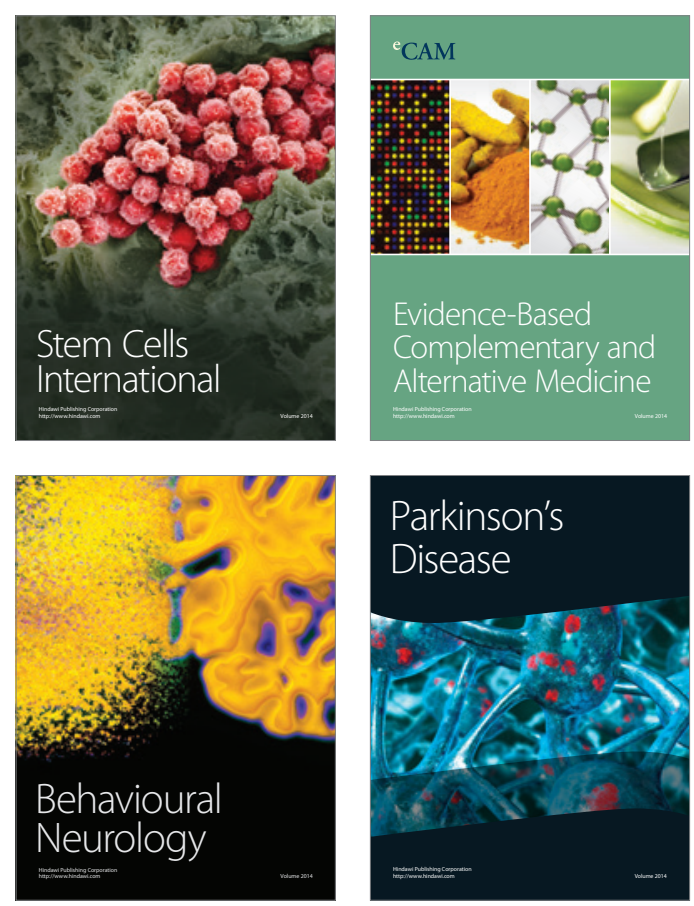

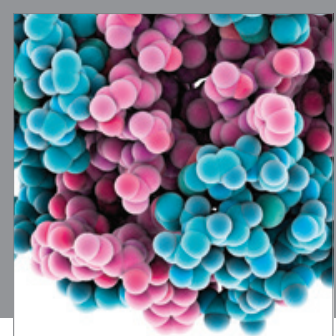

Journal of
Diabetes Research

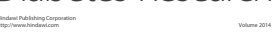

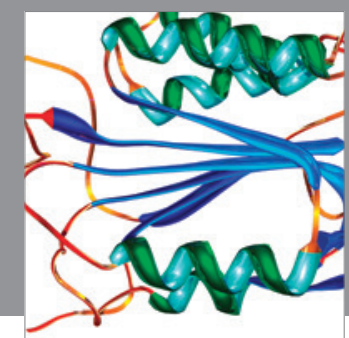

Disease Markers
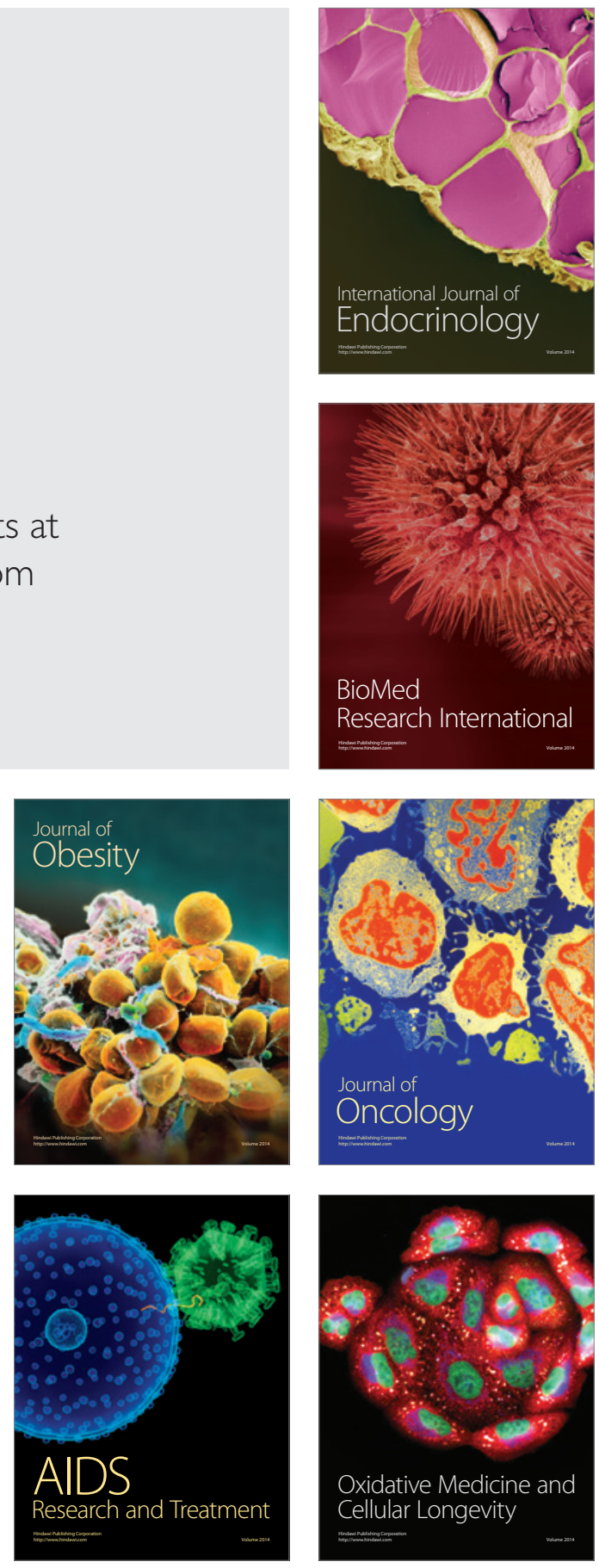